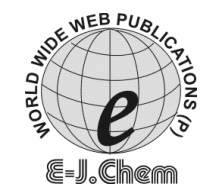

http://www.e-journals.net
ISSN: 0973-4945; CODEN ECJHAO

E-Journal of Chemistry

2008, 5(S2), 1069-1080

\title{
Spectrophotometric and Conductometric Determination of Clomiphene Citrate and Nefazodone $\mathrm{HCl}$
}

\author{
WAFAA S. HASSAN and MERVAT M. HOSNY \\ Analytical Chemistry Department, \\ Faculty of Pharmacy, Zagazig University, Zagazig, Egypt. \\ hassanwafaa76@yahoo.com
}

Received 30 December 2007; Accepted 20 February 2008

\begin{abstract}
Two accurate, rapid and simple spectrophotometric and conductometric methods were developed for the determination of clomiphene citrate (CMP) and nefazodone $\mathrm{HCl}$ (NFZ), the proposed methods depends upon the reaction of ammonium reineckate with the two studied drugs to form stable precipitate of ion-pair complexes, which was dissolved in suitable solvent. The pink colored complexes were determined colorimetrically at 509, $523.6 \mathrm{~nm}$, respectively. Using the conductometric titration, the studied drugs could be evaluated in $50 \%(\mathrm{v} / \mathrm{v})$ acetone in the range 60.02-540.18 and 63.3-443.1 $\mu \mathrm{g} \mathrm{mL} \mathrm{m}^{-1}$ for clomiphene citrate and nefazodone $\mathrm{HCl}$, respectively. While for spectrophotometric method the ranges were $0.2-1.8$ and $0.2-1.6 \mathrm{mg} \mathrm{mL}^{-1}$ for clomiphene citrate and nefazodone $\mathrm{HCl}$ respectively. Various experimental conditions were studied. The results obtained showed good recoveries with relative standard deviations of 0.759 and $0.552 \%$. The proposed procedures were applied successfully to the analysis of these drugs in their pharmaceutical preparations and the results were favourably comparable with the official and reference methods. The molar combining ratio reveal that (1:1) (drug : reagent) ion associates were formed.
\end{abstract}

Keywords: Conductometric titration, Spectrophotometric determination, Clomiphene Citrate, Nefazodone $\mathrm{HCl}$.

\section{Introduction}

Clomiphene is used for induction of ovulation. It is a mixture of $E$ and $Z$ isomers of 2-\{4-(2chloro-1,2-diphenylvinyl)phenoxy\} triethylamine dihydrogen citrate. Different methods were reported for its determination, either in pure or in dosage forms. It was determined by spectrophotometric ${ }^{1-3}$, array-type DNA glass slide ${ }^{4}$, HPLC $^{5-8}$, capillary electrophoresis ${ }^{9}$, potentiometric $^{10}$ and NMR methods ${ }^{11}$. Clomiphene was also determined in muco-adhesive oral formulation of high permeability / high solubility drugs ${ }^{12}$. 
Nefazodone hydrochloride belong to generation of antidepressant drugs, it appears to block both $5-\mathrm{HT}_{2}$ receptors. Scientific literature reports spectrophotometric method ${ }^{13}$, voltammetric technique $^{14}$, HPLC methods for quantitative determination of nefazodone HCL in its metabolites in human plasma and in pharmaceutical formulations ${ }^{15-17}$, and MS technique ${ }^{18-19}$. Nefazodone $\mathrm{HCl}$ is not included in any pharmacopoeia. With its ever increasing use and the number of formulations entering into the market, there is always a need for simple, sensitive, accurate, rapid analytical method for the estimation of it in pure form and pharmaceutical preparations which can be easily adapted for routine in quality testing laboratories. In the present study, two different techniques for the simple and accurate determination of the two drugs mentioned above were investigated.

Ammonium reineckate was used to form ion-pair complex with many drugs e.g. thioridazine ${ }^{20}$ and propranolol $\mathrm{HCl}^{21}$, the method based on precipitation of the ionassociates formed from the reaction of the drugs with ammonium reineckate. IR was reported to confirm the structure of the complex.

\section{Experimental}

\section{Apparatus}

The absorption spectra for all measurements were carried out using Shimadzu 260 recording spectrophotometer equipped with 10mm quartz cells. A CONSORT nv, Model (Parklaan 36, B2300 Tumhout, Belgium) was used. The measurement range was 1.0-10.0 $\mu \mathrm{S}$ with maximum error of $\pm 0.2 \%$. The CONSORT nv model K410 dip-type cell was used with a cell constant, $K_{\text {cell }}$, of 1.0 .

\section{Reagent}

Analytical grade reagents and double distilled water were used to prepare all solutions. Ammonium reineckate (Aldrich) was used. Clomiphene citrate pure drug and clomid ${ }^{\circledR}$ tablets, each tablet contains $50 \mathrm{mg}$ of clomiphene citrate (Global Napi Pharmaceutical, under License of Aventis Pharma S.A.E.). Nefazodone $\mathrm{HCl}$ pure drug and serzone ${ }^{\circledR}$ tablets (produced by Bristol-Myers Squibb Pharm.Ind.-Egypt), each tablet contains $200 \mathrm{mg}$ of nefazodone per tablet.

\section{Preparation of sample solutions}

Solution of $2 \mathrm{mg} / \mathrm{mL}$ was prepared by dissolving $50 \mathrm{mg}$ drug in distilled water and made up to $25 \mathrm{~mL}$ in a volumetric flask for spectrophotometric procedure. For conductometric procedure, a stock standard solutions of $2.0 \times 10^{-3} \mathrm{M}$ nefazodone and clomiphene were prepared by dissolving an exact weight of the pure analytical reagent grade drug in $70 \mathrm{~mL}$ double distilled water, to which $0.01 \mathrm{M}$ hydrochloric acid was added in a $100 \mathrm{~mL}$ measuring flask. The mixture was warmed at $50^{\circ} \mathrm{C}$ in water bath for $5 \mathrm{~min}$ and diluted to volume with double distilled water. It was agitated by an electrical shaker for $5.0 \mathrm{~min}$ then cooled to room temperature and diluted to volume with double distilled water.

Also $1 \times 10^{-2}$ and $5 \times 10^{-3} \mathrm{M}$ ammonium reineckate (Aldrich) solutions were prepared by dissolving appropriate weight in $100 \mathrm{~mL}$ double distilled water for spectrophotometric and conductometric measurement respectively.

\section{General procedures}

\section{Spectrophotometric procedure}

Aliquots containing $0.2-1.8$ and $0.2-1.6 \mathrm{mg} / \mathrm{mL}$ of clomiphene citrate and nefazodone $\mathrm{HCl}$ respectively (Tables $1 \& 2$ ) were quantitatively transferred into $10 \mathrm{~mL}$ measuring flasks. To each flask $4.3 \mathrm{~mL}$ of reagent for clomiphene and nefazodone were added. Solutions of clomiphene 
were shaken well and left for 5 minute while that of nefazodone were left for 15 minute after shaking well. Then the solutions were filtered, the precipitate was washed with water and transferred with the appropriate solvent (acetonitrile for clomiphene citrate and acetone for nefazodone $\mathrm{HCl}$ ) to $10 \mathrm{~mL}$ measuring flasks. Solutions were shaken well and made up to volume with the same solvent. Absorbance was measured at 509 and 523.6 against blank (Figure 1).

Table 1. Quantitative parameters for the spectrophotometric determination of clomiphene citrate and nefazodone $\mathrm{HCl}$ using ammonium reineckate

\begin{tabular}{lcc}
\hline \multicolumn{1}{c}{ Items } & Clomiphene citrate & Nefazodone $\mathrm{HCl}$ \\
\hline Beer's law range, mg/mL & $0.2-1.8$ & $0.2-1.6$ \\
Apparent molar absorptivity*, $\mathrm{mol}^{-1} \mathrm{~L} \mathrm{~cm}^{-1}$ & $2.6 \times 10^{2}$ & $2.5 \times 10^{2}$ \\
Sandell's sensitivity mg /mL per $0.001 \mathrm{~A}$ & $4.3 \times 10^{-5}$ & $4.9 \times 10^{-5}$ \\
Regression equation & & \\
Intercept (a) & 0.04 & 0.123 \\
Slope (b) & 0.000377 & 0.000166 \\
Correlation Coefficient ( r) & 0.9998 & 0.9999 \\
Variance & 0.57 & 0.30 \\
Detection Limit & 0.38 & 0.27 \\
\hline
\end{tabular}

*Calculated on the basis of the molecular weight of the drug.

Table 2. Determination of clomiphene citrate and nefazodone $\mathrm{HCl}$ through complexation with ammonium reineckate.

\begin{tabular}{|c|c|c|c|c|}
\hline \multirow{2}{*}{ Statistics } & \multicolumn{2}{|c|}{ Clomiphene citrate } & \multicolumn{2}{|c|}{ Nefazodone $\mathrm{HCl}$} \\
\hline & Taken, mg/mL & Recovery, \% & Taken, mg/mL & Recovery \% \\
\hline & 0.2 & 99.46 & 0.2 & 100.09 \\
\hline & 0.28 & 100.41 & 0.28 & 99.40 \\
\hline & 1.2 & 100.79 & 0.6 & 99.49 \\
\hline & 1.4 & 100.79 & 0.8 & 99.92 \\
\hline & 1.6 & 100.96 & 1.4 & 99.75 \\
\hline & 1.8 & 99.17 & 1.6 & 100.05 \\
\hline Mean* $*$ SD & & $100.26 \pm 0.761$ & & $99.95 \pm 0.55$ \\
\hline $\mathrm{N}$ & & 6 & & 6 \\
\hline SD & & 0.761 & & 0.55 \\
\hline RSD & & 0.759 & & 0.55 \\
\hline $\mathrm{V}$ & & 0.57 & & 0.30 \\
\hline SE & & 0.31 & & 0.22 \\
\hline
\end{tabular}

*Mean of three different experiments.

\section{Conductometric procedure}

A suitable aliquot (up to $44.5 \mathrm{~mL}$ ) of sample solution containing 2.5-30 mg of drug was transferred to a $50 \mathrm{~mL}$ calibrated flask and made up to the mark with $50 \%$ (v/v) acetonewater mixture. The contents of the calibrated flask were transferred to a beaker and the conductivity cell was immersed. $5 \times 10^{-3} \mathrm{M}$ ammonium reineckate solution was then added from a micro burette and the conductance was measured subsequent to each addition of 
reagent solution and after thorough stirring. The conductance was measured after 2 min of each addition was corrected for dilution ${ }^{22}$ by means of the following equation, assuming that conductivity is a linear function of dilution.

$$
\Omega_{\text {correct }}^{-1}=\Omega_{o b s}^{-1}\left[\frac{v_{1}+v_{2}}{v_{1}}\right]
$$

Where $\Omega^{-1}$ obs is the observed electrolytic conductivity, $v_{1}$ is the initial volume and $v_{2}$ is the volume of reagent added.

A graph of corrected conductivity versus the volume of added titrant was constructed and the end-point determined. $0.1 \mathrm{~mL}$ of $5 \times 10^{-3} \mathrm{M}$ ammonium reineckate is theoretically equivalent to 0.633 and $0.30 \mathrm{mg}$ of nefazodone and clomiphene respectively. The procedure takes $15-30 \mathrm{~min}$ in all.

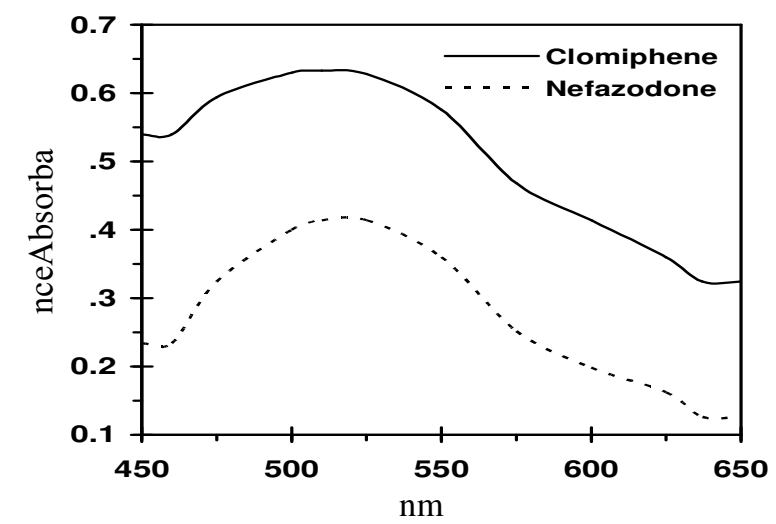

Figure 1. Absorption spectra of the complex formed through reaction of $1.6 \mathrm{mg} / \mathrm{mL}$ clomiphene and nefazodone with ammonium reineckate.

\section{Assay of pharmaceutical preparations}

The contents of 20 tablets of each of the studied drugs were thoroughly ground. A quantity equivalent to $50 \mathrm{mg}$ drug was accurately weighed into a $100 \mathrm{~mL}$ volumetric flask. The mixture was warmed at $50^{\circ} \mathrm{C}$ in a water bath for $5.0 \mathrm{~min}$, agitated by an electrical shaker for another $5.0 \mathrm{~min}$, cooled to room temperature and diluted to volume with double distilled water, filtered and the procedures was completed as under the general procedures.

\section{Results and Discussion}

Clomiphene citrate and nefazodone $\mathrm{HCl}$ were found to react with ammonium reineckate to form stable ion pair complexes. These complexes are sparingly soluble in aqueous solution, but are readily soluble in acetone or acetonitrile. Investigations were carried out to establish the most favourable conditions for the ion pair complex formation of the two drugs with ammonium reineckate to achieve sharp end point and/or maximum color development, in the determination of the drugs the influence of some variables on the reaction was tested as follow:

Conditions for spectrophotometric method

Effect of PH: The effect of PH on the precipitation of the drug-reineckate complexes was studied, different buffers were tried, it was found that buffer had no effect on the reaction. 
Effect of reagent volume: 4 and $3 \mathrm{~mL}$ of $0.01 \mathrm{M}$ ammonium reineckate solution were sufficient to give best results with clomiphene citrate and nefazodone $\mathrm{HCl}$, respectively (Figure 2).

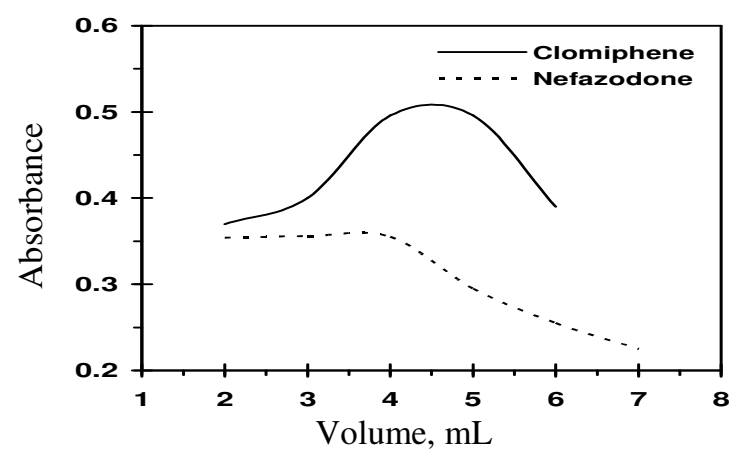

Figure 2. Effect of reagent volume on the absorbance of the complex formed with 1.2 and $1.4 \mathrm{mg} / \mathrm{mL}$ clomiphene citrate and nefazodone $\mathrm{HCl}$, respectively.

Effect of solvent: Distilled water, acetone, (acetone : water), ethanol and acetonitrile were tried. Acetonitrile and acetone were practically used to dissolve (clomiphene-reineckate) and (nefazodone - reineckate) complexes respectively.

Effect of precipitating time: 5 and 15 minute were sufficient to give complete precipitation, increasing time than this had no effect on absorption (Figure 3).

Effect of temperature: Temperature had no effect on the absorbance, so experiments were done at room temperature.

Composition of the complex: The stoichiometric ratio of the studied compounds to reineckate in the complexes were determined by applying Job's method ${ }^{23}$, the results showed that drugs and reagent react in (1:1) ratio, Figure 4.

\section{Condition for conductometric method}

Conductometric analysis can be used in many titration procedures when ionic solutions are involved. As the conductance of a solution is related to the total ionic content, it can be applied to follow reactions that result in a change in this quantity.

Conductance measurements are used successfully in quantitative titration of systems in which the conductance of the solution varies before and after the equivalence point. In these cases, the titration curve can be represented by two lines intersecting at the end point.

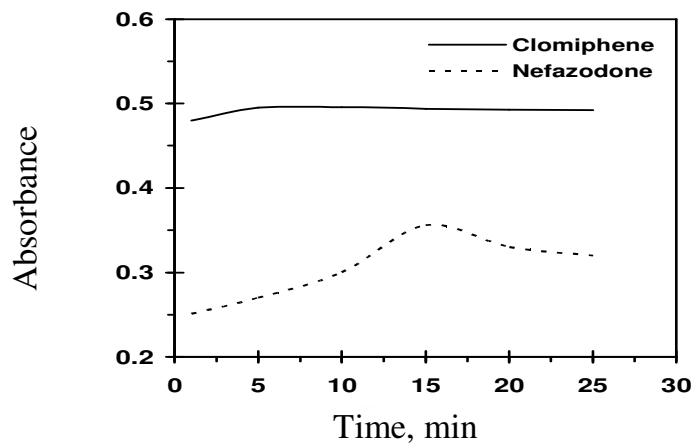

Figure 3. Effect of precipitation time on the absorbance of the complex formed through reaction of $1.2,1.4 \mathrm{mg} / \mathrm{mL}$ clomiphene and nefazodone with ammonium reineckate. 


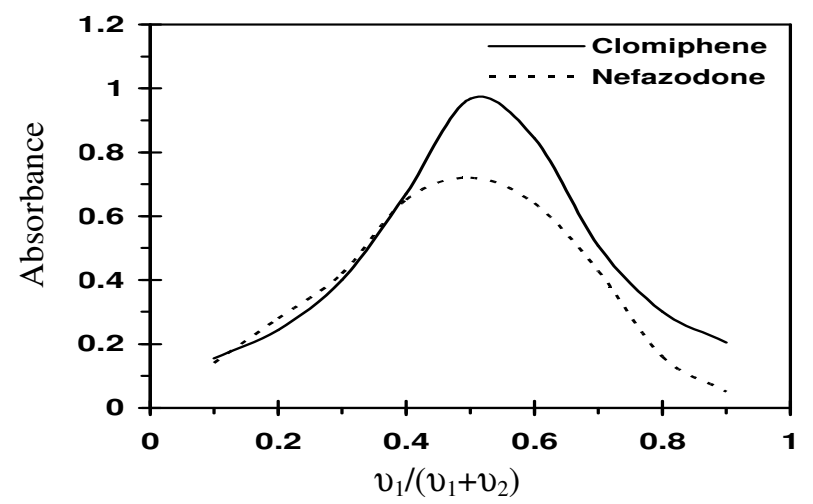

Figure 4. Continuous variation plot for $0.01 \mathrm{M}$ clomiphene citrate or nefazodone $\mathrm{HCl}$ and $0.01 \mathrm{M}$ ammonium reineckate.

Investigations were carried out to establish the most favourable conditions for the ion pair complex formation of nefazodone and clomiphene with ammonium reineckate to achieve sharp end point and/or maximum colour development, in the determination of the drug. The influence of some variables on the reaction has been tested as follow:

The optimum conditions for performing the titration in a quantitative manner were elucidated as described below. Titrations in different media were attempted to obtain the best results. Preliminary experiments in:

(i) Aqueous drug solution with aqueous reagent solution,

(ii) Ethanol drug solution with ethanol reagent solution,

(iii) Drug solution with reagent solution, both in ethanol-water $(50 \%, \mathrm{v} / \mathrm{v})$ mixture

(iv) Acetone drug solution with acetone reagent solution and

(v) Drug solution with reagent solution, both in acetone-water $(50 \% \mathrm{v} / \mathrm{v})$ mixture.

Preliminary experiments showed that procedure acetone-water $(50 \% \mathrm{v} / \mathrm{v})$ media was

the most suitable for successful results, because in other procedures precipitates were formed which caused some errors.

The reagent concentration in each titration must be not less than ten times that of the drug solution in order to minimize the dilution effect on the conductivity through the titration. The optimum concentration of the reagent was $5 \times 10^{-3} \mathrm{M}$ ammonium reineckate in titration of the two studied drugs to achieve a constant and highly stable conductance reading within 1-2 min of mixing. Concentrations less than these limits led to unstable readings and more time was needed to obtain constant conductance values. On increasing the temperature to $50^{\circ} \mathrm{C}$, no change in the conductance reading was observed, whereas above which, the conductance value changed and so changed the shape of the conductometric titration curve.

Representative titration curves are shown in (Figure 5). Two straight lines are obtained, intersecting at the end-point, the first branch ascending and the second has conductance values would remain constant or slightly increase after the equivalence point. The increase of conductance may be attributed to the formation of ion-pair in solution as a result of the complexation reaction. After the end-point, the titration curves indicate a constant or slightly increase value of conductance, despite the excess of the reagent. This may be due to further ionic condensation, leading to species of lower mobility. 


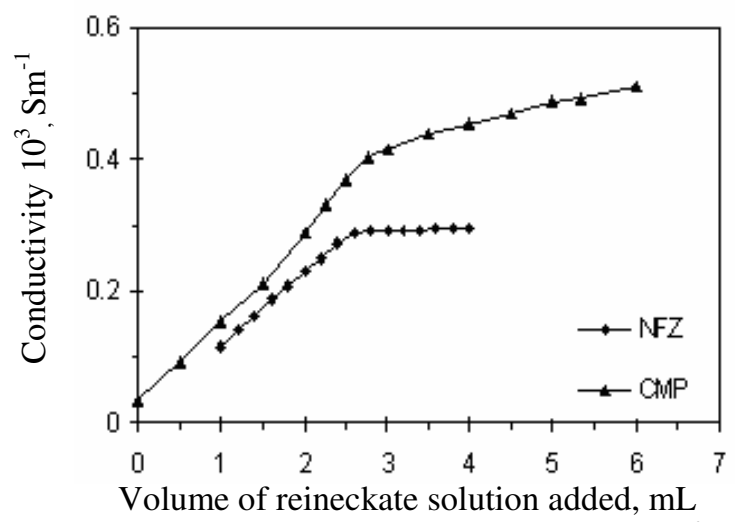

Figure 5. Conductometric titration curves of (a) $6.5 \mathrm{~mL}\left(2.0 \times 10^{-3} \mathrm{M}\right) \mathrm{NFZ}$ and (b) $6.9 \mathrm{~mL}$ $\left(2.0 \times 10^{-3} \mathrm{M}\right) \mathrm{CMP}$ vs $\left(5.0 \times 10^{-3}\right) \mathrm{M}$ ammonium reineckate.

The shape of the titration curve depends on all the species present during the titration process and other factors such as viscosity, dielectric constant, solvation, ion-pair association and proton transfer. The conductometric titrations of different volumes of $5 \times 10^{-3} \mathrm{M}$ ammonium reineckate solution in acetone-water $(50 \%, \mathrm{v} / \mathrm{v})$ mixture was performed. The results show an obvious maximum in the conductance curve at drug-reagent molar ratio of $(1: 1)$. The reactions may be represented by the equations:

$$
\mathrm{NFZ} \mathrm{HCl}+\mathrm{NH}_{4}\left[\mathrm{Cr}\left(\mathrm{NH}_{3}\right)_{2}(\mathrm{CSN})_{4}\right] \longrightarrow \mathrm{NFZ} \mathrm{H}\left[\mathrm{Cr}\left(\mathrm{NH}_{3}\right)_{2}(\mathrm{CSN})_{4}\right]+\mathrm{NH}_{4} \mathrm{Cl}
$$

The conductance of the titrated solution is mainly due to the drug cations and chloride ions and partially to the hydrogen ions resulting from the dissociation of the protonated drug cation. It was expected that the conductance values would remain constant or slightly increase after the equivalence point. However, the conductance of the solution decreased. This may be due to interaction of the protons available in the titration medium with the added reagent. Measurements of the $\mathrm{pH}$ before and after reaching the end-point for nefazodone and clomiphene, respectively, supporting the above assumption. The results from the conductometic titrations are summariezed in Tables 3-4. The data show that accurate results were obtained with good recoveries and low standard deviation values. The optimum concentration ranges for determination of the two drugs were in the range of 63.3443.1 and $60.02-540.18 \mu \mathrm{g} \mathrm{mL} \mathrm{m}^{-1}$ for nefazodone and clomiphene respectively. At such ranges, sharp inflections (Figure 5) and stable conductance reading were obtained.

Table 3. Analytical characteristic of conductometric procedure.

\begin{tabular}{lcc}
\hline Parameters & NFZ & CMP \\
\hline${\text { Optimum concentration, } \mu \mathrm{g} \mathrm{mL} \mathrm{m}^{-1}}^{\text {Shift or intercept of the regression line }}{ }^{\mathrm{a}}$ & $63.3-443.1$ & $60.02-540.18$ \\
Slope of regression line & 0.5099 & 0.0864 \\
Correlation coefficient $(\mathrm{r})$ & 0.9998 & 0.7374 \\
Relative standard deviation, $\%$ & 1.90 & 0.9992 \\
\hline
\end{tabular}

${ }^{a}$ Observed vs. theoretical; NFZ: Nefazodone HCl; CMF: Clomiphene citrate

In order to establish whether the proposed methods exhibit any fixed or proportional bias, a simple linear regression ${ }^{24}$ of drug concentration (dependent variable) against the theoretical values (independent variable) (6 points) were obtained using a programmable calculator. 
Table 4. The intra-day accuracy and precision data for the studied drugs obtained by conductometric method.

\begin{tabular}{cccccccccc}
\hline \multicolumn{1}{c}{ NFZ } \\
\hline Taken & Found & Recovery & RSD & Er & Taken & Found & Recovery & RSD & Er \\
$\mu \mathrm{g} \mathrm{mL}^{-1}$ & $\mu \mathrm{g} \mathrm{mL}^{-1}$ & $\%$ & $\%$ & $\%$ & $\mu \mathrm{g} \mathrm{mL}^{-1}$ & $\mu \mathrm{g} \mathrm{mL}^{-1}$ & $\%$ & $\%$ & $\%$ \\
\hline 63.3 & 63.62 & 100.50 & 0.46 & 0.50 & 60.02 & 59.96 & 99.90 & 0.43 & -0.10 \\
126.6 & 126.09 & 99.60 & 0.53 & -0.40 & 120.4 & 119.14 & 98.95 & 0.81 & -1.05 \\
189.9 & 188.48 & 99.25 & 0.84 & -0.75 & 180.06 & 179.16 & 99.50 & 0.70 & -0.50 \\
253.2 & 251.35 & 99.27 & 0.90 & -0.73 & 300.1 & 298.00 & 99.30 & 0.92 & -0.70 \\
316.5 & 313.81 & 99.15 & 0.43 & -0.85 & 420.14 & 419.72 & 99.90 & 0.52 & -0.1 \\
443.1 & 442.21 & 99.80 & 0.72 & -0.20 & 540.18 & 540.72 & 100.10 & 0.64 & 0.10 \\
\hline
\end{tabular}

${ }^{a}$ Average value of six determinations.

\section{Quantification}

Calibration graphs with good linearity were obtained as recorded before. The linear regression equations were also calculated. Correlation coefficient, intercept and slope values for the calibration data calculated, detection limit was also evaluated and recorded in Table 1. The Validity of the proposed methods was assessed by its application to the determination of the two drugs in their pharmaceutical preparations Tables 5-7. Student's $t$-test (at $95 \%$ confidence level) was applied to the results obtained compared with that obtained when applying the official method for clomiphene citrate or reference one for nefazodone $\mathrm{HCl}$, the results showed that it didn't differ significantly and there are no systematic differences between the proposed and official or reference methods. The results of different statistical treatment of the data are shown in Table 8 .

Table 5. Application of the proposed spectrophotometric method for the analysis of clomiphene citrate drug in dosage form

\begin{tabular}{|c|c|c|c|}
\hline Commercial product & $\begin{array}{c}\text { Claimed } \\
\text { amount, } \\
\mathrm{mg} / \mathrm{mL}\end{array}$ & $\begin{array}{c}\text { Authentic added, } \\
\mathrm{mg} / \mathrm{mL}\end{array}$ & $\begin{array}{c}\text { Recovery, } \\
\%\end{array}$ \\
\hline \multirow{5}{*}{$\begin{array}{l}\text { Clomid } ® \text { tablets } \\
\text { Each tablets contain } 50 \mathrm{mg} \\
\text { clomiphene citrate per tablet }\end{array}$} & 0.28 & --- & 101.17 \\
\hline & --- & 0.2 & 100.79 \\
\hline & --- & 0.6 & 99.02 \\
\hline & --- & 0.8 & 101.12 \\
\hline & --- & 1.2 & 101.67 \\
\hline Mean* $*$ SD & & $100.65 \pm 1.14$ & \\
\hline $\mathrm{N}$ & & 4 & \\
\hline SD & & 1.14 & \\
\hline RSD & & 1.13 & \\
\hline $\mathrm{V}$ & & 1.29 & \\
\hline SE & & 0.57 & \\
\hline
\end{tabular}

\footnotetext{
*Mean of three different experiments.
} 
Table 6. Determination of nefazodone $\mathrm{HCl}$ in its pharmaceutical preparation by using spectrophotometric method.

\begin{tabular}{ccc}
\hline Commercial product & $\begin{array}{c}\text { Label claim, } \\
\mathrm{mg} / \mathrm{mL}\end{array}$ & Found, $\%$ \\
\hline & 0.20 & 100.30 \\
Serzone tablets & 0.28 & 99.61 \\
& 0.40 & 101.35 \\
Mean \pm SD & 0.60 & 100.70 \\
$\mathrm{~N}$ & \multicolumn{2}{c}{$100.49 \pm 0.728$} \\
$\mathrm{SD}$ & 4 \\
$\mathrm{RSD}$ & 0.728 \\
$\mathrm{~V}$ & 0.725 \\
$\mathrm{SE}$ & 0.529 \\
* Mean $\pm S D$ (mean of three different experiments) \\
** & 0.364 \\
Theoretical values for t and F-values at five degree of freedom.
\end{tabular}

Table 7. Application of the proposed conductometric method to the determination of the studied drugs in dosage forms.

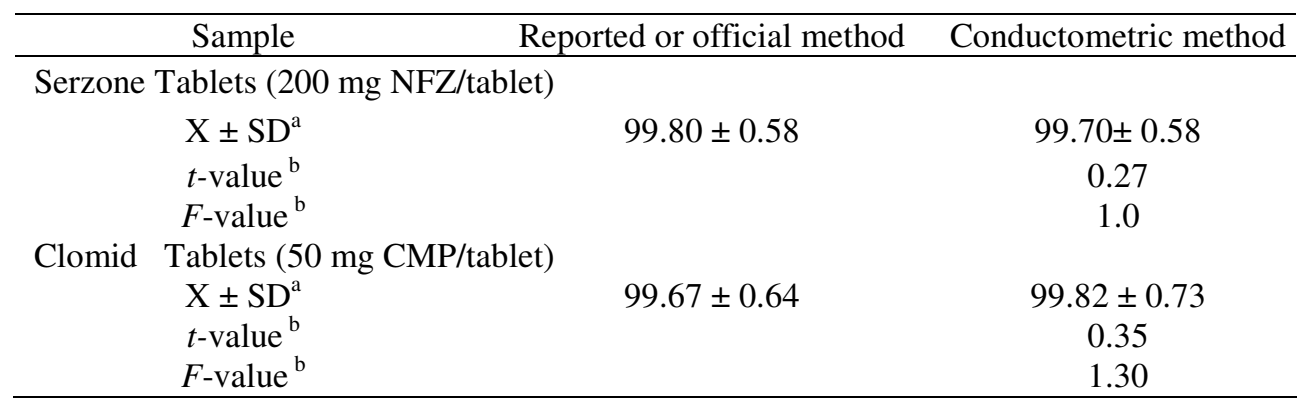

*Mean $\pm S D$ (mean of three different experiments)

${ }^{* *}$ Theoretical values for $t$ and $F$-values at five degree of freedom and $95 \%$ confidence limit.

Table 8. Determination of clomiphene citrate and nefazodone $\mathrm{HCl}$ through complexation with ammonium reineckate using Spectrophotometric method compared with official and reference one.

\begin{tabular}{|c|c|c|c|c|c|c|}
\hline \multirow[b]{2}{*}{ Statistics } & \multicolumn{2}{|c|}{ Clomiphene citrate } & \multicolumn{4}{|c|}{ Nefazodone $\mathrm{HCl}$} \\
\hline & $\begin{array}{l}\text { Official } \\
\text { method }\end{array}$ & $\begin{array}{c}\text { Spectro- } \\
\text { photometric } \\
\text { method }\end{array}$ & $\begin{array}{l}\text { Conduc- } \\
\text { tometric } \\
\text { method }\end{array}$ & $\begin{array}{l}\text { Reference } \\
\text { Method }^{13}\end{array}$ & $\begin{array}{c}\text { Spectro- } \\
\text { photometric } \\
\text { method }\end{array}$ & $\begin{array}{l}\text { Conduc- } \\
\text { tometric } \\
\text { method }\end{array}$ \\
\hline Mean*,p=0.05 & 99.56 & 99.60 & 99.95 & 99.10 & 99.61 & 100.26 \\
\hline $\mathrm{N}$ & 6 & 6 & 5 & 6 & 6 & 4 \\
\hline V & 0.57 & 0.32 & 0.45 & 0.304 & 0.452 & 0.32 \\
\hline SD & 0.81 & 0.552 & 0.673 & 0.74 & 0.761 & 0.57 \\
\hline$t$-test ${ }^{* *}$ & & $1.56(2.306)$ & $0.12(2.306)$ & & $2.14(2.262)$ & $0.743(2.262)$ \\
\hline F-test ${ }^{* *}$ & & $1.80(5.41)$ & $1.69(5.41)$ & & $0.148(5.19)$ & $1.45(5.19)$ \\
\hline
\end{tabular}

*Mean $\pm S D$ (mean of three different experiments)

${ }^{* *}$ Theoretical values for $t$ and $F$-values at five degree of freedom and $95 \%$ confidence limit. 
IR spectra (Figure 6\&7) show that complexation between clomiphene citrate and ammonium reineckate (amonium tetra thiocyanate diamine chromate) took place through ion pairing to produce clomiphene reineckate. IR chart of the resulting complex not only contain bands due to the reineckate part such as $3314,3237 \mathrm{~cm}^{-1} \mathrm{NH}_{\mathrm{s}}$ and $2077 \mathrm{~cm}^{-1} \mathrm{SCN}$, but also enclose a band at $3442 \mathrm{NH}$ of clomiphene. Moreover, The absence of $\mathrm{C}=\mathrm{O}$ absorption band at $1731 \mathrm{~cm}^{-1}$ and the broad $\mathrm{OH}$ absorption band at $3250-2500 \mathrm{~cm}^{-1}$ propose the absence of the citrate anion from the complex. As a conclusion from the above data, the complex is ion pair where protonated clomiphene replaces the ammonium cation of ammonium reineckate with a molar ration (1:1).

In the same way, IR spectra were analyzed to verify the structure of the complex formed between nefazodone $\mathrm{HCl}$ and ammonium reineckate. Again the complex is ion pairing between protonated nefazadone and reineckate with a molar ration (1:1). The IR spectrum of complex shows bands characteristic for functional groups of both parts of the salt, such as:

1. Presence of amidic $\mathrm{C}=\mathrm{O}$ at $1678 \mathrm{~cm}^{-1}$ confirms the presence of nifazadone in the complex.

2. Presence of two bands at $3295,3236 \mathrm{~cm}^{-1} \mathrm{NHs}$, in addition to the very characteristic band at $2076 \mathrm{~cm}^{-1} \mathrm{SCN}$ authenticates the presence of reineckate in the complex.

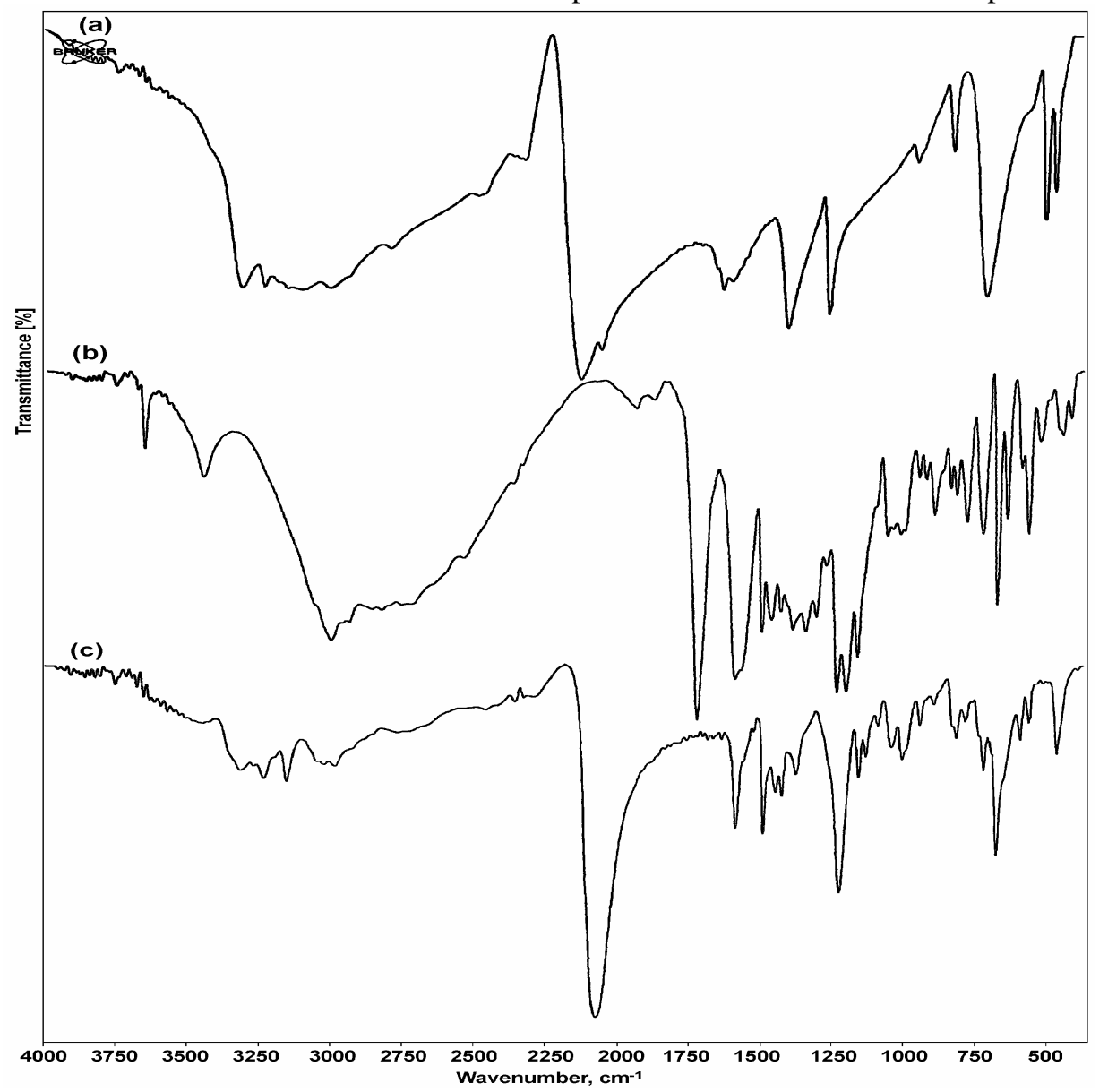

Figure 6. IR spectra of (a) ammonium reineckate, (b) Clomiphene citrate and (c) Clomiphene citrate and ammonium reineckate complex. 


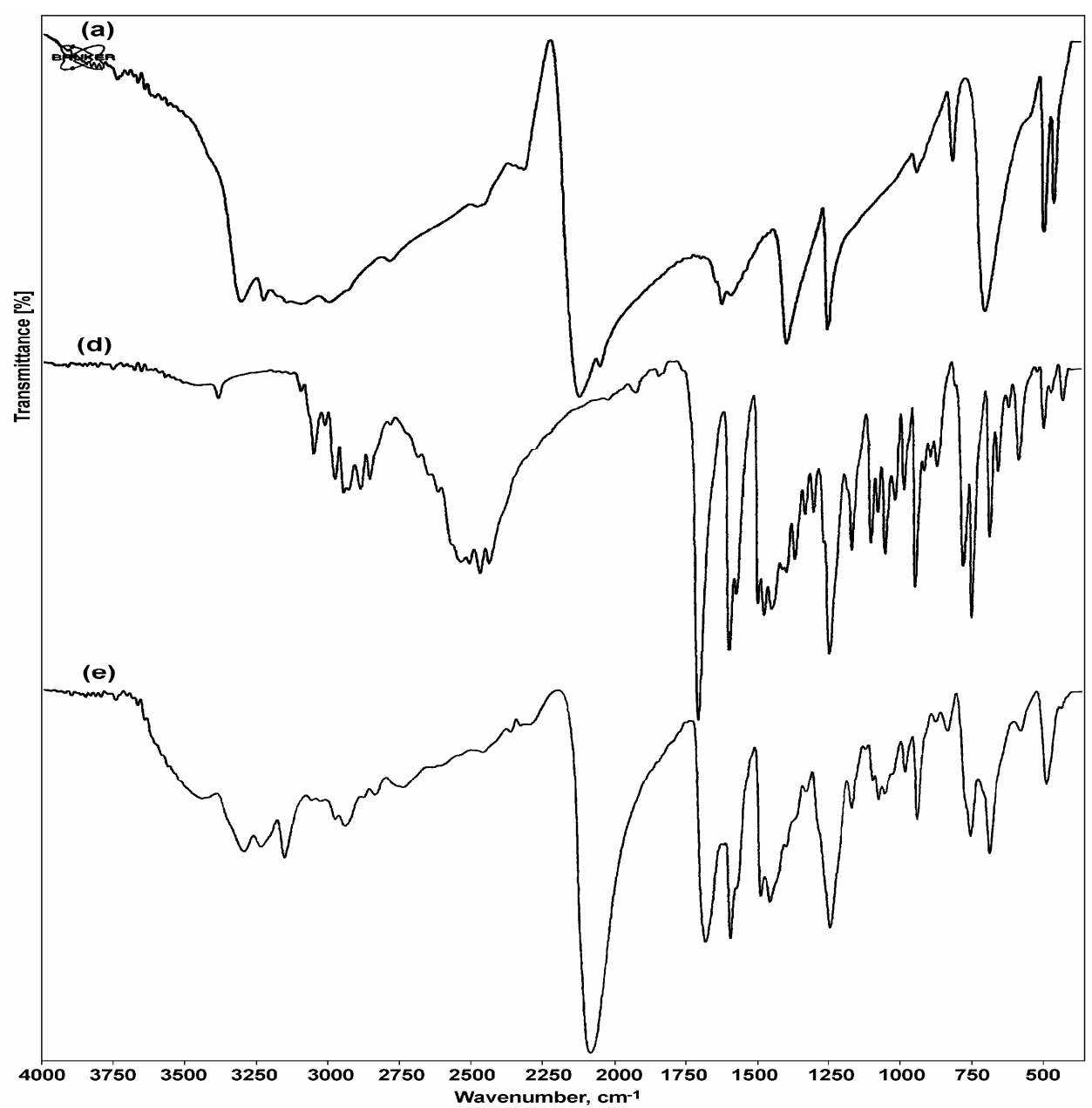

Figure 7. IR spectra of (a) ammonium reineckate, (d) Nefazodone $\mathrm{HCl}$, and (e) Nefazodone $\mathrm{HCl}$ and ammonium reineckate complex.

\section{Accuracy and precision}

In order to determine the accuracy and precision of the proposed method, solutions containing six different concentrations of each drug were prepared and six replicate determinations were carried out for the pure form and the pharmaceutical preparation of the drugs under investigation. The analytical results obtained from this investigation are summarized in Table 4. The relative standard deviation (RSD \%) as precision and percentage relative error (Er \%) as accuracy of the suggested method was calculated. The percentage relative error calculated using the following equation:

$$
\text { Er } \%=[(\text { found }- \text { added }) / \text { added }] \times 100
$$

The intra-day precision and accuracy results are shown in Table 4. These results of accuracy and precision show that the proposed method have good repeatability and reproducibility. 


\section{Conclusions}

The proposed methods have the advantages of being simple, rapid, accurate, highly reproducible and time saving, thereby encouraging its applications in quality control of these drugs in their pure form and in pharmaceutical preparations; conductometric method has the advantage over the spectrophotometric one of being more sensitive.

\section{References}

1. Hewala I I, Analytical Letters, 1993, 26, 625.

2. Rao Mallikarjuna G P V, Devi A P, Krisna Prasad K M M and Sastry C S P, Indian Drugs, 2002, 39, 395.

3. Rao Malikarjuna G P V,Aruna Devi P, Krishna Prasad K M M and Sastry C S P, J Ind Chem Soc., 2002, 79, 848.

$4 \quad$ Kim S B, Ozawa T and Umezawa Y, Anal Sci., 2003, 19, 49.

5. Uromos I, Benko S M and Klebovich, J Chromatogr., 1993, 617,168.

6. Hage D S and Sengupta A, Anal Chem., 1998, 70, 4602.

7. Sengupta A. and Hage D S, ibid., 1999, 71,3821.

8. Yue Z, Wu J and Zhang Q, Yaowu-Fenxi-Zazhi, 2006, 26(12), 1712.

9. Bempong D K and Honigberg I L, J. Pharm Biomed Anal., 1996, 15, 233.

10. Hosny M M and Elsaid H M, Alex J Pharm Sci., 2007, 21(1), 25.

11. Hays P A, J Forensic Sci., 2005, 50(6), 1342.

12. Jacob Jules S, Moslemy P, Nagia A, Zeev S and Kreitz M, Sphericinc. Patent Cooperation on Treaty Application, 2006.

13. Erk N, Farmaco, 2003, 58, 1209.

14. Usluand B and Ozkan S A, Anal Chim Acta, 2002, 462(1), 49.

15 Franc J E, Duncan G F, Farmen R H and Pittman K A, J. Chromatogr Biomed Sci Appl., 1991, 570, 129.

16. Rao S, Geetha, Srinivasu M K and Reddy G O, J. Pharm Biomed Anal., 2001, 26, 629.

17. Rao R N and Nagaraju V, J. Pharm Biomed.Anal., 2003, 33(3), 335.

18. Jemal M, Ouyang Z, Zhao W P, Zhu M S and Wu W W, Rapid Commun Mass Spectrum., 2003, 17(24), 2732.

19. Leuthold L A, Mandscheff J F, Fathi M, Giroud C, Augsburger M, Varesio E and Hopfgartner G, Rapid Commun Mass Spectrum., 2005, 20(2), 103.

20. Tarasiewicz M and Kuzmicka L, Pharmazie, 1996, 51(3),189.

21. Murillo-Pulgarin J A, Alanon A and Fernandez P, Anal Chim Acta, 1998, 370(1), 9.

22. Lingane J J, Electroanalytical Chemistry, $2^{\text {nd }}$ Ed., Interscience, New York, 1958, 90.

23. Incezdy J, Analytical Application of Complex Equilibiria, Ellis Horwood Ltd., England, 1976, 137.

24. Miller J C and Miller J N, Statistics in analytical Chemistry, $3^{\text {rd }}$ Ed., Ellis Horwood, Chichester, UK, 1993. 


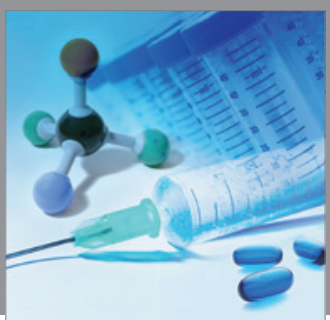

International Journal of

Medicinal Chemistry

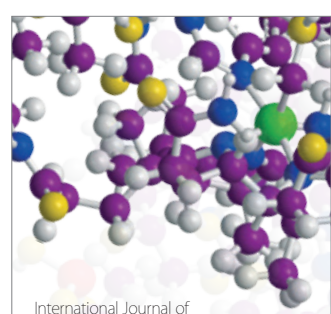

Carbohydrate Chemistry

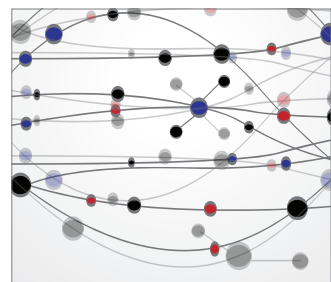

The Scientific World Journal
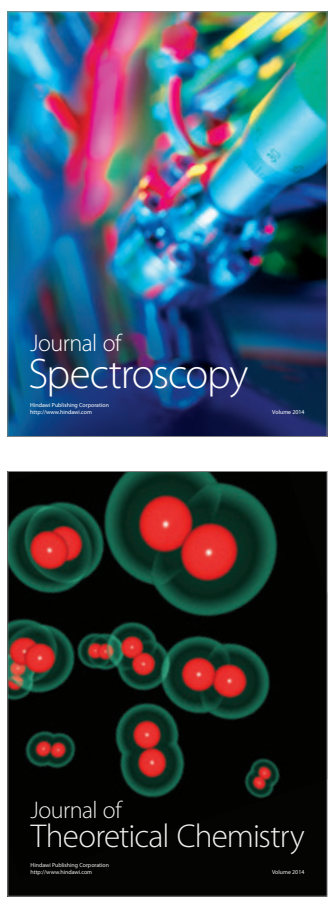
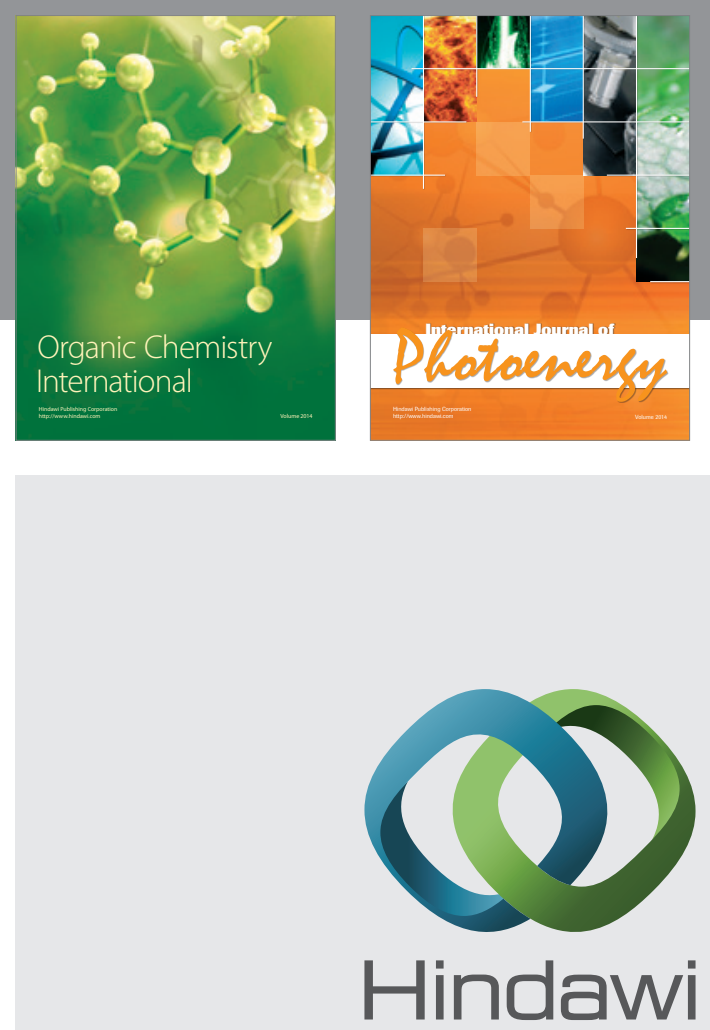

Submit your manuscripts at

http://www.hindawi.com
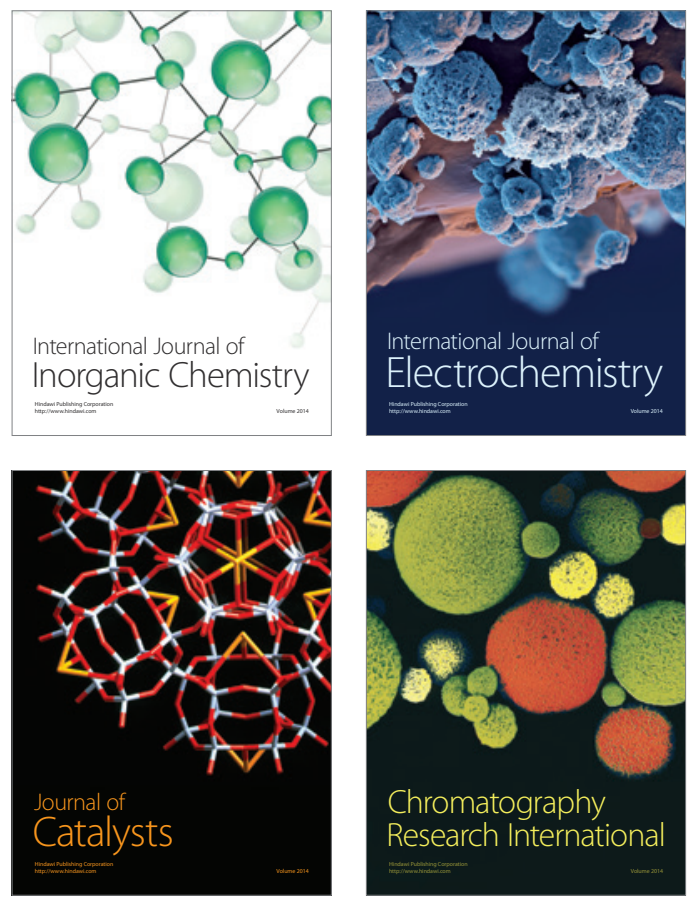
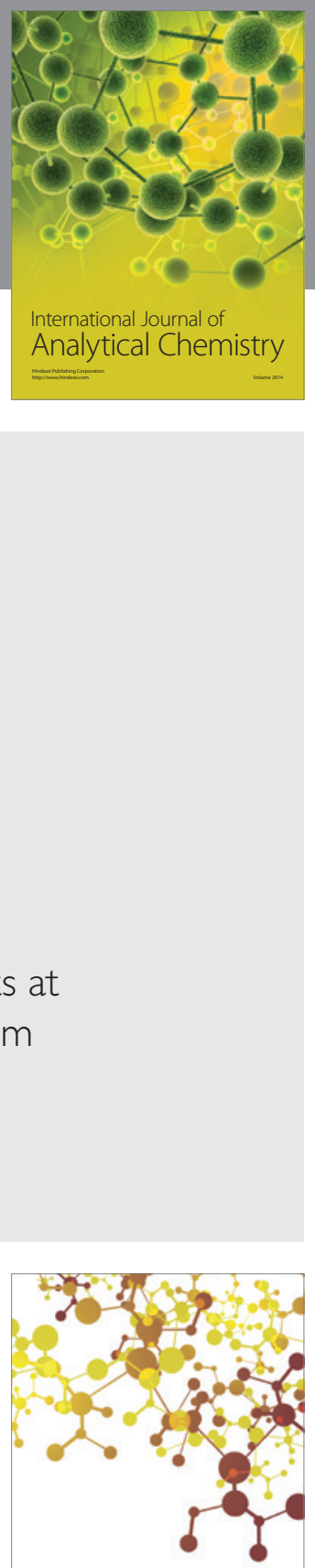

Journal of

Applied Chemistry
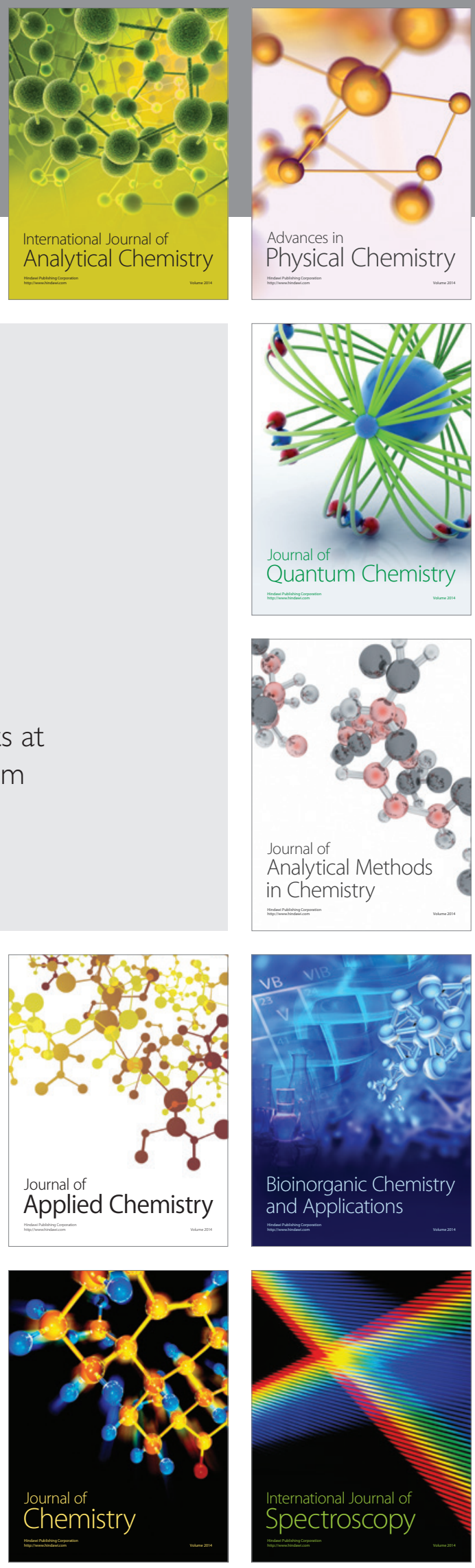